\title{
HABITANDO OS CAMPOS DA ARTE E DA TERAPIA OCUPACIONAL: PERCURSOS TEÓRICOS E REFLEXÕES ${ }^{*}$
}

\section{INHABITING THE ART'S AND THE OCCUPATIONAL THERAPY'S FIELDS: THEORETICAL COURSES AND REFLECTIONS}

\author{
Eliane Dias de Castro ${ }^{(1)}$, \\ Dilma de Melo Silva ${ }^{(2)}$
}

CASTRO, E. D.; SILVA, D. M. Habitando os campos da arte e da terapia ocupacional: percursos teóricos e reflexões. Rev. Ter. Ocup. Univ. São Paulo, v. 13, n. 1, p. 1-8, jan./abr. 2002.

RESUMO: O acompanhamento de pessoas desenvolvendo atividades artísticas nas práticas ocorridas no âmbito da Terapia Ocupacional, provocou uma curiosidade sobre as relações que ocorrem entre este 'fazer' e a promoção da saúde. Ao transitarmos no universo das Artes pelo viés da Terapia Ocupacional vivenciamos práticas interdisciplinares e pesquisamos autores que em suas proposições teóricas indicam ressonâncias entre estes campos. Neste artigo relatamos como ocorreu este processo, apresentamos algumas bases teóricas que sustentam nossa prática e reflexão e as etapas aproximativas que pudemos identificar a partir dos estudos realizados. Este material é parte de um capítulo teórico de minha tese de doutorado, que vem ampliar os estudos das atividades e recursos terapêuticos e fornece uma nova consistência teórica ao ensino das atividades artísticas na Terapia Ocupacional.

DESCRITORES: Terapia pela arte/métodos. Acesso aos serviços de saúde/tendências. Terapia ocupacional/métodos. Saúde mental. Valores sociais.

"Os limites da minha linguagem denotam os limites do meu mundo"

(Rubem Alves parodiando Wittgenstein)

$\mathrm{P}$ ara conhecer, aprofundar e configurar os propósitos da arte nos atendimentos e práticas de Terapia Ocupacional, foram necessárias múltiplas ações e tempo de amadurecimento para identificarmos quais inter-relações entre estes dois campos de conhecimento poderiam ser consideradas fundamentais, que justificariam a opção pelas atividades artísticas em diversos momentos da prática profissional.

Desse modo foi necessário formular aproximações e, em seguida, acrescentar outras, em sucessivas etapas, fornecendo a idéia de um trabalho que se configura como uma progressão teórico-prática

\footnotetext{
(*) Adaptação do capítulo 3: Aproximações, da tese de doutorado, intitulada - Atividades Artísticas e Terapia Ocupacional: construção de linguagens e inclusão social - apresentada ao Departamento de Comunicações e Artes da ECA/USP, em 2001.

(1) Docente do Curso de Terapia Ocupacional do Departamento de Fisioterapia, Fonoaudiologia e Terapia Ocupacional da Faculdade de Medicina da USP. Mestre em Artes e Doutora em Ciências pelo Departamento de Comunicações e Artes da Escola de Comunicações e Artes da USP.

(2) Professora do Programa de Pós-Graduação da Escola de Comunicações e Artes da USP, Departamento de Comunicações e Artes.

Endereço para correspondência: Centro de Docência e Pesquisa em Terapia Ocupacional da FMUSP. Rua Cipotânea, 51. CEP: 05360-160. São Paulo, SP. e-mail: elidca@usp.br
} 
por meio de etapas aproximativas. Transitamos no tema da Arte de diversas formas: através do acompanhamento de pacientes na realização de atividades artísticas; inserindo-me e atuando em programas de atendimento à população com propostas de arte, independentemente do diagnóstico clínico; estudando e pesquisando bibliografias e aspectos teóricos sobre o tema; participando de cursos como aluna e, organizando cursos como professora na graduação e, posteriormente, na especialização. Isto conferiu à esta etapa e à este processo de construção do conhecimento, experiências e vivências que se referem ao fazer artístico, ao contato com metodologias de ensino da arte, ao desenvolvimento de procedimentos na atuação terapêutica ocupacional, ao reconhecimento da interação entre o processo e o produto nas atividades artísticas, sobre o lugar da obra na vida dos sujeitos atendidos, e sobre a importância das construções teóricas neste campo de conhecimento e de seu caráter transdisciplinar.

Artistas, arte-educadores, psicólogos, sociólogos, antropólogos, historiadores, terapeutas ocupacionais e educadores se relacionam de diferentes formas e em diferentes momentos com esta questão. Cada particularidade pensada e vivenciada num desses campos pode produzir uma ressonância nos outros ou ainda, percursos já trilhados podem sinalizar novas trajetórias, novos entendimentos.

Este processo tornou-se um desafio, pessoal e de um grupo de trabalho - aqui me refiro às pessoas, profissionais, docentes e alunos, que integram e integraram o Laboratório de Estudos e Pesquisa Arte e Corpo em Terapia Ocupacional do Curso de Terapia Ocupacional da Faculdade de Medicina da USP, no período entre 1998 a 2002 - cujo objetivo desdobrouse no ato de construir lenta e pacientemente um campo de ação prática interligado a conceitos que, no seu processo de assimilação, tornam-se fundamentais e, à medida que a construção teórica progride, as interconexões entre os campos de atuação tornam-se mais precisas.

Imergir nos territórios da Arte, pelo viés da Terapia Ocupacional nos conduz a um confronto com um campo de conhecimento, um universo fascinante constituído de materialidade, espiritualidade, criação, referências, dificuldades, um caminho de busca. Este movimento proporciona um fazer que pressupõe sensibilidade, observação, improvisação, expressão e composição através do desenvolvimento das linguagens artísticas.

No percurso para compreender tal universo, envolver-se com ele, experienciar práticas que eduquem os sentidos, apreciar diferentes formas de arte e contextualizá-las, realizar estudos teóricos, descobre-se que deste envolvimento curioso e gradual, excitante e ressonante, operam-se mudanças internas e externas, ocorrem rupturas provisórias, verdadeiras desconstruções, criam-se novos vínculos, forma-se "um impulso indagador genuíno" que não parte de filosofias externas, mas das situações vivenciadas e de como tais experiências vão tornando-se parte da existência.

\section{BASES TEÓRICAS}

Para começarmos é fundamental situarmos a Arte no sistema das atividades humanas. Um olhar que pode propiciar o início do nosso entendimento teórico, com base nos estudos do 'fazer artístico', é a proposição de Kagan (1987), esteta russo, que procura estudá-la neste contexto. Em sua perspectiva, a origem da arte baseiase em uma ação prática que apresenta qualidades, capacidades e mecanismos internos que podem ser desdobrados em leis objetivas do seu funcionamento real. A história do desenvolvimento do pensamento estético mostra uma variedade de concepções e programas subjetivos desenvolvidos por teóricos e estudiosos da arte, críticos, artistas e amantes da arte que caracterizam e a definem de formas bastante abrangentes. Segundo este autor:

a arte foi criada pela humanidade como uma espécie de duplicação de sua atividade vital real, com a função de ampliar a experiência da vida prática do homem e complementá-la com a experiência da 'vida em arte', uma experiência organizada com mais efetividade que a experiência real, formada de maneira espontânea (KAGAN, 1987, p. 215, trad. autora).

Nesta perspectiva, o entendimento do que é arte cria a anterior necessidade de uma apresentação sobre a estrutura da atividade vital real do homem, cujas bases referem-se à sua realidade como ser social e a seu relacionamento com 'o seu em torno material' estabelecendo assim, um sistema de relações que se desenvolvem em dois níveis: um nível prático e um nível espiritual.

O nível prático refere-se à transformação prática da realidade, é mais simples e pode ser caracterizado pelas relações entre o sujeito e o objeto visando satisfazer as exigências e necessidades dos sujeitos e ainda, compreende uma outra perspectiva que é a interação entre os sujeitos.

O nível espiritual é mais complexo de ser analisado e refere-se à atitude da relação espiritual dos sujeitos sobre os objetos abordando também a relação 
entre os sujeitos. A relação espiritual dos sujeitos sobre os objetos pode ser definida como atividade cognitiva ou de formação do conhecimento humano e, neste caso, o mundo objetivo é contemplado pelo sujeito em suas próprias leis. A relação espiritual entre os sujeitos é definida como comunicação seja qual for o sistema de sinais em que ela se dê, em que ela se expresse.

Assim, a estrutura da atividade vital real do homem, é na realidade, a estrutura que dá a base de sua atividade social, composta por quatro elementos com funções fundamentais, definidas em: trabalho ou transformação prática da realidade, conhecimento, comunicação e orientações valorativas. Estas atividades combinam-se organicamente entre si.

Para Kagan (1987), a arte é o modelo ideal da atividade humana pois integra essas quatro funções, numa união sincrética, promovendo uma fusão orgânica de total coincidência desses elementos, que regulam o sistema de atividade humana. $\mathrm{O}$ resultado desta fusão orgânica destes quatro elementos é uma atividade singular definida como atividade artística.

$\mathrm{Na}$ atividade artística, o conhecimento da realidade está contido na experiência do sujeito que transforma, através da sua imaginação, um elemento da realidade num novo objeto que, até então, não constituía a realidade. A partir da atividade artística surge um elemento que é 'criação sobre o mundo real' e que configura-se como uma forma de 'apropriação artística' do mundo.

A arte é uma forma de conhecimento da realidade e das leis da existência real do homem. Ela é a transformação idealizada desta realidade e possibilitadora da criação de uma nova realidade. É produto da imaginação artística do mundo, na qual trabalho, conhecimento, comunicação e valoração se fundem na criação do que não existe, nunca existiu e não pode existir no mundo e, é imprescindível que este conteúdo artístico possa ser comunicado através das diversas possibilidades de linguagem: verbal, gestual, imagética, sonora, ou arranjos e composições entre elas. A arte educa o homem, proporciona prazer estético e sua verdadeira finalidade é ser um meio de comunicação entre as pessoas, por sua abrangência ela torna-se uma linguagem especial.

Em sua estrutura, ela é flexível e plástica, expressa a dialética entre o durável e o variável, o imutável e o mutável. Nela há a identificação dos contrários, a luta dos contrários e a aparição de novas qualidades no conjunto, não encontradas nos elementos que a compõe. Em todas suas modificações morfológicas e históricas a arte apresenta esta estrutura fundamental, que é a mesma apesar de experimentar, ao longo do tempo, as mudanças mais radicais. Aí está sua principal qualidade, o valor artístico, sua propriedade específica, sua qualidade integradora das ações humanas.

Na atividade artística não há a exigência de que seus produtos sejam reconhecidos como realidade, ela caracteriza-se como criação de um modelo de realidade e não a realidade mesma. Ela é, segundo Kagan (1987), um dos mais relevantes descobrimentos da sensibilidade humana, pois refere-se à criação de uma herança sóciocultural e de seus mecanismos de transmissão de experiências socialmente valiosas para os indivíduos e, para o equilíbrio e bem-estar geral da humanidade (p. 221).

Para ele, se analisarmos todas as formas concretas da atividade humana constituídas no processo histórico da divisão social do trabalho, verificaremos que isto provocou no homem uma autodesagregação e um isolamento de um determinado tipo de atividade em relação às demais. Entretanto, esta capacidade de dissociar-se é o resultado de um alto nível de desenvolvimento psíquico, no qual o homem deve aprender a romper com a sua unidade interna que, por um lado, apresentou os benefícios da especialização mas, que ao mesmo tempo, produz aspectos prejudiciais, muitas vezes, manifestados de forma dolorosa proporcionando uma unilateralidade e o sentimento de um 'homem incompleto' (KAGAN, 1987, p. 226).

Schiller (1995), ao posicionar-se sobre este aspecto, nos alerta de que ao

romper com a unidade interna da natureza humana provoca-se uma divisão de suas forças, encadeia-se eternamente um pequeno fragmento isolado do todo. O homem torna-se fragmento, não é capaz de desenvolver a harmonia do seu ser e ao invés de expressar o humano de sua natureza se converte em reflexo de sua ocupação, de sua ciência (p. 67).

A pessoa que realiza atividades artísticas em seu processo de concentração para a ação, têm a possibilidade de reunir fragmentos de suas experiências e transformá-los em novos elementos ampliando, com isso, sua experiência de vida prática e complementandoa com um conteúdo espiritual. A este processo Kagan (1987) denominará de experiência da 'vida em arte' experiência organizada com mais efetividade que a vida real. A arte, então, procede da experiência vivida, é atividade que visa mergulhar-nos na significação dos gestos e ações da vida, estabelece relação com aspectos materiais, está ligada aos valores espirituais do homem, representa o processo cultural de um grupo social, podendo apresentar-se como um fator ativo de 
organização social. Relacionada a estes últimos aspectos temos a noção de que a arte permite que o homem possa agir sobre seu próprio meio desempenhando também uma função de comunicação social.

Além do mais, verificamos que a arte pode ser compreendida por múltiplos enfoques. Silveira (1992) identifica na arte um veículo para a auto-expressão do indivíduo, e vê como qualidade terapêutica das atividades artísticas a possibilidade de dar formas à emoções tumultuosas, despotencializando-as (p. 17).

Por outro lado, segundo a concepção de Ostrower (1995), na arte encontramos a possibilidade de entendimento de vivências que apresentam contextos dentro de outros contextos, ou de contextos simultâneos característicos de padrões de vivências independentes embora interligadas entre si, que apresentam-se como expressão da condensação das experiências vividas, para a autora: "A fonte da criatividade artística, assim como de qualquer experiência criativa, é o próprio viver. Todos os conteúdos expressivos na arte, (...), são conteúdos essencialmente vivenciais e existenciais (p. 7).

A arte constitui-se como um importante recurso no campo terapêutico pois as linguagens artísticas são provenientes da sensibilidade, da percepção e da experiência dos sujeitos, elas são mais flexíveis que a linguagem verbal, necessariamente se estruturam e se reestruturam em função de projetos específicos. Os detalhes de qualquer forma de arte - como tocar um instrumento, representar uma peça, pintar um quadro, esculpir uma pedra, desenhar uma árvore, dançar um tema - são naturalmente específicos, assim como os são os materiais, as técnicas, os procedimentos e as metodologias de ensino para cada arte. Os termos concretos das diversas linguagens artísticas são inteiramente diferentes entre si, porém, seus princípios ordenadores são análogos. Nas linguagens artísticas,

(...) existe uma espécie de metaconhecimento, um metafazer que ultrapassa estilos e formas (...). Embora certos princípios se apliquem a um campo particular, existem outros aplicáveis a todos os campos da atividade criativa. Toda ação pode ser praticada como arte, como ofício ou como obrigação (NACHMANOVICH, 1993, p. 21).

A estruturação da linguagem artística, diversamente da linguagem verbal, configura-se como uma linguagem própria, constituída por um caminho de sensibilidade que permeia os significados criados. É uma linguagem expressiva, na qual os conteúdos expressivos são articulados através de formas, de imagens, de cores, algumas vezes de modo verbal como nas linguagens poéticas e, muitas vezes, de modo nãoverbal, abrangendo aspectos racionais ou intuitivos, com a presença de narrativas ou de formas não-discursivas.

A linguagem artística consegue formular a complexidade e a fluidez dos sentimentos e a integração de vários níveis de significados (pessoais, familiares, de um determinado grupo, de uma determinada cultura, etc...). Impressões, improvisações e composições ganham força expressiva nesta linguagem e assim, podemos tomar conhecimento das possibilidades singulares de cada sujeito, abrir novas rotas criativas, reunir conhecimentos de diversas áreas, dar início a novos processos.

Nelas encontramos princípios básicos que dizem respeito à matéria da linguagem e, também, a

ritmos, tensões, e estados de equilíbrio interno, nossos e das configurações que criamos. Mas não podem existir formas expressivas pré-estabelecidas, que sejam válidas para todas as pessoas em todas as circunstâncias. Pois o universo que encontramos na arte é o das vivências e da expressão de experiências de vida (...) E são múltiplas as respostas que, em cada caso, podem tornar-se válidas (OSTROWER, 1995, p. 206).

Um outro aspecto fundamental na estruturação das linguagens artísticas que devemos considerar, é o fato de que ela é cheia de símbolos. Jung (1987) considera que os símbolos são termos, nomes ou imagens, que podem ser familiares na vida cotidiana, embora possuam conotações além de seu significado evidente e convencional. Para ele, existem inúmeras coisas fora do alcance da compreensão humana e, freqüentemente utilizamos termos simbólicos como representação de conceitos que não podemos definir ou compreender integralmente. São elementos que proporcionam um aprofundamento em aspectos do viver e por conseqüência, podem desenvolver-se e constelar uma consciência que permite desdobrar e reconhecer experiências vividas, algumas vezes não identificadas ou não percebidas imediatamente.

A partir do fazer artístico é possível completar experiências que ficaram destituídas de sentido e significado ou criar novos sentidos e significados para experiências vividas e, ainda, este fazer permite também acessar a dimensão inconsciente da natureza humana.

O homem, (...), nunca percebe plenamente uma coisa ou a entende por completo (...); em um determinado momento há de chegar a um limite de evidências e de convicções que o conhecimento consciente não pode transpor (JUNG, 1987, p. 21).

Jung (1987) observa que há aspectos inconscientes na nossa percepção da realidade. Toda 
experiência contém um número indefinido de fatores desconhecidos e toda realidade concreta sempre tem aspectos que ignoramos, desconhecemos. Segundo ele, há acontecimentos que permanecem abaixo do limiar da consciência. Aconteceram, mas foram absorvidos subliminarmente, sem nosso conhecimento consciente. Só podemos percebê-los em momentos de intuição ou por um processo de intensa reflexão, que nos leva à subsequente realização de que podem ter acontecido. São de importância emocional e vital e, brotam do inconsciente como uma espécie de um 'segundo pensamento’ (JUNG, 1987, p. 23).

Este 'segundo pensamento' pode aparecer, por exemplo, na forma de um sonho, na forma de mitos e nas representações artísticas. É ele que nos proporciona o conhecimento do inconsciente, e o inconsciente é a matéria que nos permite um conhecimento total da psique humana. Para Jung (1987), a psique faz parte da natureza e seu enigma é, igualmente, sem limites.

Nas nossas experiências cotidianas, o inconsciente participa de tudo, capta percepções subliminares que influenciam a maneira por que vamos reagir a fatos e pessoas. Conteúdos conscientes podem desvanecerse no inconsciente e, novos conteúdos, que nunca foram conscientes, podem 'emergir'.

\begin{abstract}
A descoberta de que o inconsciente não é apenas um simples depósito do passado, mas que está também cheio de germes de idéias e de situações psíquicas futuras levou-me a uma atitude nova e pessoal quanto à psicologia (...) o fato é que, além de memórias de um passado consciente longínquo, também pensamentos inteiramente novos e idéias criadoras podem surgir do inconsciente - idéias e pensamentos que nunca foram conscientes. Como um lótus, nascem das escuras profundezas da mente para formular uma importante parte da nossa psique subliminar (JUNG, 1987, p. 37-8).
\end{abstract}

Encontramos exemplos disso em nossa vida cotidiana, e também nos trabalhos artísticos desenvolvidos pelas pessoas atendidas, onde às vezes soluções surpreendentes e novas proposições se constelam. Grande parte de idéias, inspirações e resoluções dos trabalhos artísticos nascem repentinamente do inconsciente. É, também, a partir da experiência artística que reconhecemos a capacidade de nossa psique alcançar um veio particularmente rico deste material inconsciente, e transformá-lo de maneira eficaz e particularmente significativa para a vida de cada sujeito. Neste contexto, encontramos uma gama de variações e nuances indescritíveis nas experiências, particularmente devido ao tom emocional presente em cada experiência, própria para cada pessoa. As forças do inconsciente manifestam-se na atividade artística e em todas as outras atividades culturais através da qual o homem se expressa, são forças que aparecem em praticamente todos os campos da atividade humana.

Para Read (1982), a experiência artística tratase fundamentalmente de um "envolvimento com o fenômeno orgânico e mensurável e está profundamente envolvido no processo real de percepção, pensamento $e$ ação. É um mecanismo orientador e sem ele a civilização perde o seu equilíbrio e cai no caos espiritual e social (p. 83).

Os campos da arte têm suas próprias leis de atividade e, como toda realização criadora, não podem ter uma explicação racional definitiva. A dimensão simbólica da atividade artística representa tentativas naturais para a reconciliação e, união dos elementos antagônicos da psique. A linguagem da arte é um dos muitos modos de conhecer o mundo e a cultura de cada lugar, de conhecer o outro e de conhecer a si mesmo. O estudo da Arte nos propõe o contato com um universo da história da civilização humana, seu entendimento coloca-a como entidade linguística e cultural. Nela, as reestruturações da linguagem respondem a mudanças de valores, de anseios e de buscas no seio da cultura e da sociedade.

\section{ARTE E TERAPIA OCUPACIONAL}

Na perspectiva da Terapia Ocupacional, o conhecimento dos componentes intrínsecos da atividade artística é essencial quando o terapeuta faz uso deste recurso. Resgatar a unidade nas atividades dos sujeitos parece ser fundamental nos processos de restabelecimento da saúde. A presença destas atividades na organização do cotidiano estimulam o organismo e atuam como catalisadores dos processos de restabelecimento e melhora da saúde dos indivíduos e, um novo potencial de vida é ativado, novos projetos surgem. As atividades artísticas auxiliam na recomposição de universos de subjetivação e de resingularização das atividades das pessoas, constituemse de linguagens que permitem o compartilhar de experiências, o entendimento de concepções de mundos; e, com isso, auxiliam na compreensão de padrões de vivências que precisam ser completadas e integradas plenamente na experiência de vida dos sujeitos. São enriquecedoras das experiências de vida e instrumentos para a comunicação entre as pessoas.

Uma ampliação deste sentido nos é dada por Guatarri (1991), quando visualiza na arte uma possibilidade de:

catalisar operadores existenciais suscetíveis de adquirir 
consistência e persistência, (...), catálise poéticoexistencial que se apresentará na obra, (...), cuja eficiência reside essencialmente na capacidade de promover rupturas ativas, processuais, no cerne das tramas significacionais, (...), a partir das quais introduzirá novos universos de referência (p. 15).

O acompanhamento de pessoas atendidas em Terapia Ocupacional na realização das atividades artísticas, demonstra que é fato observável a melhora da disposição e da saúde dos indivíduos quando vivenciam tais processos. No decorrer desses anos de trabalho e investigação, ficou-me claro que a atividade artística que se desenvolve com bases na livre-expressão têm sua finalidade terapêutica e representa um momento específico no acompanhamento de pessoas. Ela permite conhecer situações vividas e as habilidades do sujeito e, em alguns momentos, é o único instrumento possível para dar vazão à determinados conteúdos expressivos que não podem ser verbalizados. Mas, no decorrer do trabalho e com bases em novas propostas de Reabilitação, novas metodologias podem ser empregadas e um trabalho de educação estética dos indivíduos surpreende com a qualidade dos trabalhos que podem surgir.

A metodologia de ensino da arte baseada na livreexpressão, é históricamente relacionada ao Modernismo, muito utilizada no campo terapêutico, enfatiza a importância da expressão e prescreve a idéia de que arte é interioridade, valorizando mais o processo vivenciado pelos sujeitos do que o produto, caracterizando o fazer artístico principalmente como algo proveniente do mundo interno do indivíduo, como um processo de auto-descoberta.

Só a partir dos anos 90, é que outras metodologias de ensino da arte foram pesquisadas e utilizadas no campo da Terapia Ocupacional, associadas, então, às novas orientações no campo da reabilitação, fortemente marcadas pela preocupação da inclusão sócio-cultural dos indivíduos. Esta reorientação metodológica pode ser associada ao Pós-Modernismo cujo fazer artístico apresenta ênfase na elaboração, na reorganização, na desconstrução e na reconstrução, influência das práticas interdisciplinares, dando ao processo e ao produto importância semelhante, pois, será a partir do produto que poderá se deflagrar outros processos, compartilhados também a partir de novos produtos, e assim sucessivamente, com bases nas idéias contemporâneas de que Arte é projeto, eSaúde é projeto de vida.

Já em 1970, Napolitani apud Righetti (1970), psicanalista italiano, chamava a atenção para o fato de que no interno da clínica existiam ateliês de pintura, escultura, entre outras atividades artísticas às quais, os pacientes eram convidados a expressarem-se livremente, como uma linguagem de tipo artístico pois, à elas se atribuíam valor diagnóstico e terapêutico, o que conferia às obras e à vida dos pacientes um juízo restrito. Muitos psiquiatras sustentavam a necessidade de estimular o doente a algum tipo de atividade artística, enquadrável porém, no campo diagnóstico. Para este fato, há um entendimento crítico e uma nova proposição. FrayzePereira (1995), apresenta o teor crítico de tal atitude:

\begin{abstract}
Este ato se ordena em torno da norma, em termos do que é normal ou não, do que se deve ou não fazer. (...) Trata-se de um poder epistemológico, poder de extrair dos indivíduos um saber, de extrair um saber sobre esses indivíduos já submetidos ao olhar e já controlados pelos diferentes poderes. Trata-se, portanto, de um saber sobre os indivíduos que nasce de sua observação, de sua classificação, da análise de seus comportamentos, da sua comparação etc (p. 127-8).
\end{abstract}

Para Napolitani (1970), criar uma equivalência entre expressividade artística e tratamento são fatores de grande mistificação. O profissional que não intui o que se move, o que se agita no ser humano que tem diante de si, não entenderá absolutamente nada de um desenho ou de uma escultura.

Indubitávelmente, porém, ser-lhe-á mais fácil construir um arabêsco de palavras ao redor das manchas de côr, que enfrentar uma relação real com o paciente, ante o qual, o mais das vezes, não sabe reagir a não ser com punhados de pílulas ou com eletrochoque (NAPOLITANI apud RIGHETTI, 1970, p. 44).

Sua reflexão transcorre no entendimento de que ninguém põe em dúvida que facilitar, em um ser humano, a possibilidade de comunicação seja de grande importância quando a linguagem comum não permite ao sujeito exteriorizar as próprias angústias. $\mathrm{O}$ paciente engendra novos meios de comunicação, palavras, sons e gestos para tentar se comunicar porém, ao ser humano que se comunica e se exprime de modo 'diverso', é acompanhado o senso de vergonha pela sua diversidade.

Com este sistema de expressão artística oferecese uma ponte de criação entre o paciente e os outros. No interno da clínica este tipo de comunicação é encorajada e valorizada. Pode ser concebida como uma modalidade espontânea, por meio do qual o paciente tenta seu contato com o mundo, identificando a incapacidade dos outros, receptores da comunicação, em geral a sociedade, de escutar e de entender.

Cada paciente, quando realiza uma atividade artística faz mais que expor a si mesmo e o próprio sofrimento: ele realiza um fato de cultura. No momento em que 
contribui para abrir uma fenda naquela muralha intransponível, no costume atual, entre os que se exprimem de certa forma e os que, nessa forma, não encontram a si mesmos, o doente opera um ato de cultura ( ...) Penso que Arte é a expressão da condição humana da qual, tanto o 'doente' quanto o 'não-doente' participam (NAPOLITANI, 1970 apud RIGHETTI, 1970, p. 47).

Estas idéias apresentam-se como um dos pilares do nosso pensamento e de nossa prática, os pacientes quando realizam atividades artísticas no campo terapêutico ocupacional estão realizando um fato de cultura. Esta perspectiva fornece-nos uma concepção nova das linguagens artísticas no campo clínico e, as considerações que emergem destas produções indicam caminhos de intervenção prática que suscitam questões abrangentes e de profunda importância.

O estudo e acompanhamento de pessoas com deficiências, usuários de serviços de saúde mental, pessoas com problemas orgânicos, crianças marginalizadas, idosos, enfim populações heterogêneas na realização de atividades artísticas abre-nos um campo de conhecimento que podemos chamar de caminho de humanização. Este termo surge das observações que permitem o entendimento da importância desta linguagem para a condição humana. Esta experiência mostra-nos que:

boa parte do que é distintivamente humano em nós nossas capacidades de linguagem, pensamento, comunicação e cultura - não se desenvolve de maneira automática, não se compõe apenas de funções biológicas, mas também tem origem histórica e social; essas capacidades são um presente - o mais maravilhoso dos presentes - de uma geração para a outra. Percebemos que a cultura é tão importante quanto a natureza.(..) Se esse tema nos mostra as vulnerabilidades, os modos como (muitas vezes inadvertidamente) podemos prejudicar a nós mesmos, ele nos mostra, da mesma forma, nossas forças desconhecidas e inesperadas, os infinitos recursos de sobrevivência e transcendência com que nos dotaram, juntas, a natureza e a cultura (SACKS, 1998, p. 11).

No campo da Terapia Ocupacional nos deparamos com uma enorme diversidade cultural associada à dificuldades de expressão e comunicação dos indivíduos. São elementos associados que estão presentes nos indivíduos, com doenças ou deficiências ou em processo de desfiliação social, e derivam das formas pelas quais a família e a sociedade mais próxima lida e se relaciona com o problema. Isto provoca na prática profissional do terapeuta ocupacional a necessidade de encontrar meios para possibilitar a expressão e a comunicação das pessoas e entre as pessoas que revitalizem a existência, que operem como linguagem e favoreçam a inclusão social e, o engajamento na cultura. O que está em jogo neste campo terapêutico, que fundamentalmente não se diferencia de outros campos de trabalho com a saúde, são questões referentes à vida em seu aspecto orgânico, psíquico, social e cultural, seu caráter criativo, a necessidade de trabalho e do reconhecimento da função de cada um no campo social e, a noção da constante necessidade de construção da linguagem.

\begin{abstract}
Nesta perspectiva, deficiência, distúrbios e doenças podem ter um papel paradoxal, revelando poderes latentes, desenvolvimentos, evoluções, formas de vida que talvez nunca fossem vistas, ou mesmo imaginadas, na ausência desses males. Nesse sentido, é o paradoxo da doença, seu potencial 'criativo', apresentando caminhos diferentes de pessoa para pessoa (SACKS, 1995, p. 130).
\end{abstract}

Na Terapia Ocupacional, através das linguagens artísticas podemos potencializar a participação e o acompanhamento do desenvolvimento da atualização cultural e engendrar formas de novas experiências sociais. Projetos singulares favorecem caminhos de desenvolvimento linguístico que temos chamado de caminhos de construção de poéticas pessoais.

\begin{abstract}
Este caminho, que parte da criação do próprio indivíduo para sua contextualização na cultura e na sociedade é amparado pelo procedimento técnico da terapia ocupacional (...), na intersecção que esta abordagem proporciona entre o pedagógico e o terapêutico. Ensinar a fazer atividades, aprender e apreender que o fazer se faz com as próprias mãos, e nessa produção cada um escreve a sua própria história.(...) Na clínica da terapia ocupacional, construímos artesanalmente, e artísticamente (acréscimo nosso), pois é uma produção única - a possibilidade de cada um ser reconhecido e se reconhecer por outros fazeres" (TEDESCO, 1997, p.17).
\end{abstract}

\section{CONCLUSÃO}

Na Terapia Ocupacional, as atividades artísticas assumem um importante lugar, pois apresentam-se como um sistema de ampliação e potencialização de possibilidades, que se transformam em autoconhecimento e aprofundam a experiência do viver. A criação artística resulta de processos no qual o sujeito compreende e articula a realidade de sua experiência de vida. As produções sempre envolvem um diálogo com a consciência através da sensibilidade e da percepção, e como vimos tocam o inconsciente. As obras referemse a experiências, cujos componentes individuais podem divergir ou contrastar entre si, podem apresentar 
conteúdos complexos, multifacetados, sintéticos e, tornam-se fonte de luta e de prazer. Elas enriquecem a experiência do sujeito porque favorecem o crescimento pessoal, possibilitam uma maior liberdade no viver, podendo alcançar um valor social.

A arte, por natureza, é desalienante, é um instrumento para conhecer-se e conhecer a realidade; nesse sentido ela é 'terapêutica' e, por natureza 'profilática'. Ela abre para o sujeito um campo de aquisições, habilitações e prevenções e, pode apresentarse como um mecanismo de alegria, tensão, prazer e fortalecimento nos processos de potencialização e inclusão social e cultural. Para ainda caracterizarmos a linguagem artística precisamos entendê-la como uma atividade altamente integradora de outros campos de atividade de cada pessoa. A partir dela, reconhecemos limitações e possibilidades, efetivamos novas conexões e novas áreas da vida podem se expandir.

CASTRO, E. D.; SILVA, D. M. Inhabiting the art's and the occupational therapy's fields: theoretical courses and reflections. Rev. Ter. Ocup. Univ. São Paulo, v. 13, n. 1, p. 1-8, jan./abr. 2002.

\begin{abstract}
S: The people's attendance developing artistic activities in the Occupational Therapy practices, stimulated a curiosity about the relationships among this actions and the promotion of health. As we move through the universe of Arts from the Occupational Therapy's slant we expirenced interdisciplinares practices and researched authors that indicate resonances among these fields in their theoretical propositions. In this article we told how this process happened, we presented some theoretical bases that sustain our practice and reflection and the nearness stages that we could identify from the accomplished studies. This material is part of a theoretical chapter of my doctorate thesis, that comes to enlarge the studies of the activities and therapeutic resources and supplies a new theoretical consistence to the teaching of the artistic activities in the Occupational Therapy.
\end{abstract}

KEYWORDS: Art therapy/methods. Health services accessibility/trends. Occupational therapy/methods. Mental health. Social values.

\title{
REFERÊNCIAS
}

CASTRO, E. D. Atividades artísticas e terapia ocupacional: construção de linguagens e inclusão social. 2001. Tese (Doutorado) - Escola de Comunicações e Artes, Universidade de São Paulo, São Paulo, 2001.

FRAYZE-PEREIRA, J. A. Olho d'água. Arte e loucura em exposição. São Paulo: Escuta, 1995.

GUATTARI, F. Linguagem, consciência e sociedade. In: SAÚDE e loucura 2. São Paulo: Hucitec, 1991

JUNG, G. C. O homem e seus símbolos. Rio de Janeiro: Nova Fronteira, 1987.

KAGAN, M. El arte en el sistema de la actividad humana. In: ESTÉTICA, selección de lecturas. La Habana: Editorial Pueblo y Educación, 1987.

LIMA, E. M. F. A. Identidade e complexidade: composições no campo da terapia ocupacional. Rev. Ter. Ocup. Univ. São Paulo, v. 10, n. 2/3, p. 42-5, 1999.

NACHMANOVITCH. Ser criativo. O poder da improvisação na vida e na arte. São Paulo: Summus, 1993.

NAPOLITANI, 1970 apud RIGHETTI, 1970.

OSTROWER, F. Acasos e criação artística. Rio de Janeiro: Campus, 1995.

READ, H. A educação pela arte. Lisboa: Edições 70, 1982.

RIGHETTI, D. O limiar da arte. Rasegna Med. Cultural, v. 8, n. 4, p. 44-53, 1970.

SACKS, O. Antropólogo em marte. São Paulo: Cia das Letras, 1995.

SACKS, O. Vendo vozes. São Paulo: Cia das Letras, 1998.

SCHILLER, F. A educação estética do homem. São Paulo: Companhia das Letras, 1990.

SILVEIRA, N. O mundo das imagens. São Paulo: Ática, 1992.

TEDESCO, S. Terapia ocupacional: produzindo uma clínica de atenção às dependências. Rev. Centro Estudos Ter. Ocup., v. 2, n. 2, p.16-9, 1997.

Recebido para publicação: 10/10/2001

Aceito para publicação: 05/11/2001 